\title{
STUDY ON PHYSICOCHEMICAL AND SENSORY CHARACTERISTICS OF EGGLESS YELLOW CAKE
}

\author{
${ }^{* 1}$ FMNA, Aida, , ${ }^{1} \mathrm{AZ}$, Nor Anida and ${ }^{1} \mathrm{Z}$, Norasmanizan \\ Food Science and Technology, Faculty of Applied Sciences, Universiti Teknologi MARA, 40450, Shah Alam, Selangor, Malaysia. \\ Tel: +603-55435602,*E-mail: aidafirdaus@uitm.edu.my
}

\begin{abstract}
Practicability of full substitution of eggs in the production of yellow cake was evaluated. Different concentrations of xanthan gum were used $(0.5 \%, 1.0 \%$ and $1.5 \%)$. The results showed that substituting eggs with $0.5 \%$ xanthan gum inside a cake produced a harder cake and lower its volume, water activity, and moisture content compared to control (1599.66 and $1945.69 \mathrm{~g}, 523.33$ and 425.00 $\mathrm{cm}^{3}, 0.91$ and $0.89,28.87$ and $26.97 \%$, respectively). The sensory evaluation result showed that the addition of $0.5 \%$ xanthan gum to an eggless cake received the highest acceptability among other eggless cakes. In conclusion, the addition of $0.5 \%$ xanthan gum produced the most promising egg substitute in cakes.
\end{abstract}

Keywords — eggs; xanthan gum; eggless yellow cake

\section{INTRODUCTION}

Yellow cake is one of the simplest types of cake to be produced and its principal ingredients consist of flour, eggs, oil, milk, and sugar. Each ingredient plays an important role in their specific function towards the final quality of the cake [1]. Eggs, in particular, provide many functions to baked goods. This includes giving structure to the cake as air is being mixed into the batter when it is being beaten, provides colour and flavour to baked goods, and it also acts as an emulsifier between liquid ingredients and fat [2].

A traditional cake ingredient (yellow cake, pound cake) however usually consists of eggs, making them unsuitable for consumers who are allergic to eggs and lacto-vegetarians. Those allergic to egg cannot consume most cakes in the market due to its egg content which contains proteins such as ovotransferrin, ovalbumin, ovomucoid, and lysozyme can cause symptoms such as itchiness, atopic dermatitis, vomiting, bronchial asthma and rhinitis [3]. Lacto-vegetarians are known to eliminate any type of meat or eggs in their diet. However, unlike other types of vegetarian diets, they still consume dairy products such as milk, cheese and yoghurt [4]. Besides that, eggs are known for its high cholesterol content that can be linked to cardiovascular diseases if consumed in large amount and it is the most costly ingredients in the cake making industry [5].

Xanthan gum is a type of hydrocolloids produced from the fermentation of Xanthomonas campestris, a gram-negative bacterium, commonly produced at an industrial scale. Its application on food as a stabiliser and emulsifier was approved by the U.S. Food and Drug Administration (USFDA) without any restrictions [6]. Xanthan gum is suitable to be used as thickener, stabiliser, and suspender in many food products due to its excellent ability to become soluble and at the same time, stable in alkaline solutions, and are also able to resist to degradation at a wide range of $\mathrm{pH}$ levels and elevated temperatures [7]. Polysaccharides (xanthan gum, guar gum, and Arabic gum, for instance) are usually added as baking additives in order to improve the shelf-life of baked goods and they are commonly added in combination with emulsifiers for foam stabilising and as flavour enhancer [8]. For example, the incorporation of egg replacers in producing eggless yellow cake and found that the blends of xanthan gum, whey protein isolates, and wheat starch is the best egg replacer in producing a suitable yellow cake system, besides delivering functionality at a fairly low cost [9]. In this study, the lowest gum concentration to be used was at $0.5 \%$, which was based on a study in determining the optimum level of xanthan gum to be added in the production of eggless cake [5]. This value is then increased by $0.5 \%$ to $1.0 \%$ and $1.5 \%$, which is the most commonly used concentration of xanthan gum added to the eggless cake, for the former.

However, previous studies conducted only focuses on the quality of eggless cake produced, without determining the chemical contents of the cake such as fat, protein and carbohydrate content $[5,8,10]$. This study would provide information on the effects of substituting eggs with xanthan gum to the quality of a normal yellow cake which will be beneficial to the food industry in producing cakes that can be consumed by both lacto-vegetarians and people who are allergic to egg. Besides that, it would also provide information on whether substituting eggs in a cake with xanthan gum caused a significant effect to the physicochemical and sensory characteristics of yellow cake based on the data obtained. The main objectives of this study were to deduce the physicochemical properties and sensory characteristics of eggless cake substituted with xanthan gum. 


\section{MAterial AND Methods}

\section{A. Material}

The yellow cake recipe was adapted from a previous study [10], with slight modifications. Table 1 lists the recipe of the control cakes and eggless yellow cakes with different substitutes denoted by F1, F2, and F3 with xanthan gum concentrations of $0.5 \%, 1.0 \%$ and $1.5 \%$ (based on flour basis), respectively. The ingredients used were obtained from a local supermarket which includes wheat flour, vegetable oil, fine granulated sugar, baking powder, eggs (grade B), and vanilla essence and food grade xanthan gum was obtained from a local supplier. All chemicals are of the analytical grade for analysis purposes are sulphuric acid, catalyst mixture (potassium sulphate and selenium), sodium hydroxide, boric acid, hydrochloric acid, and petroleum ether.

\section{B. Methods}

\section{Preparation of cake batter and baking}

The ingredients used were weighed using an analytical balance. Weighed dry ingredients were sifted three times into a mixing bowl and were mixed with a whisk to combine. Then, all the weighed wet ingredients were added into the bowl. All ingredients were mixed together using an electric hand mixer for 3 minutes at medium speed until all ingredients were fully incorporated, avoiding any lumps formation. The cake batter was then poured into a lightly greased cake tin and was baked in a preheated oven $\left(180^{\circ} \mathrm{C}\right)$ for at least 35 minutes or until the skewer inserted into the centre comes out clean. The cake was left to cool in the baking tin to room temperature before it was removed and placed in an airtight container. The formulation of eggless yellow cake was shown as in Table 1.

\section{Chemical analysis}

Eggless yellow cakes were analysed for moisture, ash, fat, and protein [11], and carbohydrate content was determined by difference.

Carbohydrate $(\%)=100-($ protein + fat + moisture + ash $)$ in grams per $100 \mathrm{~g}$ of food.

\section{Physical characterisation of cake}

The rapeseed displacement method was used to determine the cake volume as described in the Approved Methods of the AACC (2000) [12]. A portable colorimeter (KONICA MINOLTA, CHROMA METER CR-400, Japan) set for $L^{*}$ (lightness), $a^{*}$ (redness), and $b^{*}$ (yellowness) values was used to measure the colour of cake crumb. The results of the $L^{*}, a^{*}$ and $b^{*}$ values were averaged from triplicates [13]. Using the AQUA-LAB (Decagon Devices Inc., USA) water activity meter, the water activity of the cake was determined.

\section{Textural properties of cake}

Cake samples were cut into cubes of $2.5 \times 2.5 \times 2.5 \mathrm{~cm}$ sizes. The crust of the cake samples was removed, leaving only the crumb part of the cake. A TA-XT2i plus texture analyser (Stable Micro Systems Ltd., Surrey, UK) with a 25 mm cylinder probe was used to perform a double compression test on the cake samples. The texture parameters that were recorded were hardness, cohesiveness, springiness, and gumminess.

\section{Sensory evaluation}

Thirty untrained panellists were informed that they will be evaluating eggless yellow cake. They received four samples and was asked to give ratings on each sample based on their degree of liking of the cake samples using a nine-point hedonic scale $(\mathbf{1}=$ extremely dislike, $\mathbf{5}=$ neither like nor dislike, 9 = extremely like). Cake samples were cut into cubes of $2.5 \times 2.5 \times 2.5 \mathrm{~cm}$ sizes. The crust of the cake samples was removed, leaving only the crumb part of the cake. The samples were placed in a transparent, covered and labelled containers, identified with random three-digit numbers. The panellists evaluated the samples in a special testing area with separations between panellists to avoid bias error. Using the sensory evaluation form given to each panellists, they were instructed to rinse their mouths with plain water before and between sample tasting.

\section{Statistical analysis}

The Statistical Package for Social Sciences (SPSS) version 15.0 (SPSS, Chicago, IL, USA) was used to carry out all statistical analyses in this study. A one-way analysis of variance (ANOVA) was used for the determination of the differences among groups. All data obtained were reported as means \pm standard deviations (S.D).

\section{Result AND Discussion}

\section{Chemical analysis}

Based on Table 2, the control cake contained the highest moisture content at $28.87 \%$, followed by the eggless cake with $0.5 \%, 1.0 \%$ and $1.5 \%$ xanthan gum with moisture contents of $26.97 \%, 26.18 \%$, and $25.86 \%$, respectively. There was a reduction of approximately $6.5 \%$ in the moisture content between control and the eggless yellow cake containing $0.5 \%$ gum. It was also found that eggless yellow cake with highest gum concentration at $1.5 \%$ showed the lowest moisture content by showing a decrement by $10.43 \%$ from control. The results showed that as the gum concentration increased, the moisture content decreased. A similar pattern can be observed where it also found that cakes added with hydrocolloids have reduced moisture content compared to control $[5,8,10]$. The decrease in moisture content is most probably caused by the poor ability of the eggless cake to retain its moisture [10], hence more moisture will be released throughout the baking process and during storage compared to control. This result 
might also be due to the nature of an egg. An egg contains approximately $75 \%$ of water of the edible portion of the egg which greatly contributed to the moisture content of the final product [14]. Thus, control which contains eggs has relatively higher moisture content compared to eggless yellow cakes.

The eggless cake also has significantly reduced fat content compared to the control cake. The control cake, which contains $50 \mathrm{~g}$ of egg (egg white and whole egg yolk) contains the highest fat content at $15.68 \%$. Meanwhile, all eggless yellow cake's fat content ranges between 9.99\% - 9.24\%, a decrement of approximately $36.31 \%$ from the control. A similar pattern can be found in which they also found a reduction in fat content of cake in which the egg was partially substituted with chia gel compared to control [15]. The fat (total lipid) made up approximately $9.94 \%$ of the edible portion of a whole egg [14]. From the results, it was clearly shown that the egg added into the cake greatly affected the fat content of the cake produced since the egg itself contributed a significant amount of fat to the final product.

For ash content, a decrement of approximately $31.83 \%$ between control and F3 containing 1.5\%. Moreover, there exists no significant difference in the ash content between the eggless cakes of different formulations. The ash content in the edible portion of an egg is $0.86 \%$ [14]. Since an egg contains a significant amount of ash, hence this might be the cause of the reduction of ash content in the eggless cakes.

Based on the results obtained, we can also observe that all the eggless cakes have protein content ranges between $5.76 \%$ $5.47 \%$. Meanwhile, the control cake contained the highest protein content at $7.98 \%$. A decrement of $27.82 \%$ in the protein content between control and eggless cake with $0.5 \%$ gum. It also proved in cakes with its egg content partially substituted by $75 \%$ with chia gels [15].

Results also showed that control cake has the lowest carbohydrate content at $46.25 \%$. Meanwhile, F2 and F3 contain significantly the highest carbohydrate content at $57.83 \%$ and $58.60 \%$. Both F2 and F3 were significantly different from F1. An increment of approximately $18.09 \%$ between the control cake and F1, 2.36\% between F1 and F2 and $1.30 \%$ between F2 and F3. It also found a similar pattern in the decrement of carbohydrate content in a cake which its egg content was partially removed to be substituted with chia gels compared to control [15].

The control cake was found with the highest water activity compared to the eggless cakes at 0.91 . The water activity of the control cake in their study was $0.93[16,17]$, which was almost similar to what was found in this study. For the rest of the eggless yellow cakes, the water activity ranges from 0.90 to 0.89 . The water activity of eggless cake reduced by $2.19 \%$ from control. Water activity above 0.90 lies in high water activity foods. High water activity indicates that the cakes are prone to microbial deterioration since most food microorganisms require a high amount of free water and an abundance of nutrients for growth.

\section{Physical characterisation of cakes}

Table 3 shows the volume of the cakes. Based on the results, it was found that control cake's volume was significantly the highest $\left(523.33 \mathrm{~cm}^{3}\right)$ compared to others. The volume of F1 showed a decrement of approximately $18.79 \%$ from the control. F2, on the other hand, showed less percentage of decrement at approximately $14.69 \%$ from control and F3 showed a decrement of $15.29 \%$ from control. From this result, we may conclude that the removal of the egg will significantly reduce the volume of a cake. It was also found that the addition of a higher concentration of gum added will significantly increase the cake's volume. The addition of hydrocolloids usually produces cakes with lower volumes than the control and is related to its batter consistency and density [18]. Cake batters added with hydrocolloids was found to be denser and more viscous than control. The increase led to a lower air retaining capacity of the batter during baking, hence producing cakes of lower volumes. Figure 1 shows the difference in the volume of the cake produced based on its cross-section.

Table 4 shows the colour of cake crumb (L*, a*, b* values). Control cake shows the lightest in colour as its $\mathrm{L}^{*}$ value is the highest compared to the rest at 71.32. F2 showed the least light in colour at 65.40 and F3 showed the lightest in colour for eggless yellow cake at 67.25. It also showed a similar pattern in $[9,10]$. This may due to the difference in cake volume. Higher cake volume gives more surface area as compared to cake with a smaller volume.

In $\mathrm{a}^{*}$ values, control showed an average value of -0.08 , which falls in the negative value. The negative value indicates greenness, although due to its very minute values, our naked eyes cannot tell the presence of green colour. As for the rest of the eggless yellow cakes, all of it ranges in the positive value, which indicates redness. F2 showed lower redness at 0.42 , followed by F1 at 0.46 and the eggless yellow cake with the highest redness value is F3 at 0.51 . The colour reading for $\mathrm{a}^{*}$ value for their control cake also showed a negative value at 0.04 [10], which is slightly lower than what was found in this study. For the $b^{*}$ values which indicate the yellowness (positive value), results showed that the control cake has the most intense yellow colour compared to the eggless cakes at 27.28. As for the rest of the eggless yellow cake, the $b^{*}$ values range between 23.65 and 23.19. A decrement of approximately $13.31 \%, 14.99 \%$ and $13.53 \%$ between control and F1, control and F2 and control and F3, respectively. The control cake showed $a^{*}$ value of 24.56 [10], which is less yellow compared to in this study. As for the eggless yellow cakes, it ranges between 25.97 (contains PPI and $0.1 \%$ xanthan gum) to 19.70 (contains PPI, $0.1 \%$ Xanthan gum and SL). Therefore, we can conclude that different mixtures of 
hydrocolloids and emulsifiers greatly affect the colour of the finished product.

\section{Textural properties}

Table 5 shows the results for the texture profile analysis of the eggless cake. Results showed that control cake has the least hardness at $1599.66 \mathrm{~g}_{f}$. As for the eggless yellow cakes, we can observe that the hardness increase with the gum concentration. F1 showed an increment of hardness by $17.78 \%$ from control, followed by $11.68 \%$ increase in hardness when $1.0 \%$ xanthan gum was added in F2 and lastly, an increment of only $6.18 \%$ between F2 and F3. Results showed that higher xanthan gum added will produce a harder cake, which is not preferable to the market. The similar results also shown in this study $[5,8,9,10,13,18,19]$. For example, the hardness of eggless cake (produced by substituting eggs with isolated pea protein and $0.1 \%$ xanthan gum) increased to $1050.1 \mathrm{~g}_{f}$ from $362.3 \mathrm{~g}_{f}$ (control) [10]. The cakes containing eggs had higher foaming capacity, resulting in a highly aerated cake which leads to a lower degree of hardness [20]. Another possible reason why eggless cakes were harder than control could also be due to the thickening effect of xanthan gum [5].

In the springiness parameter, the control cake and F3 showed significantly the highest springiness at 0.90 compared to the rest of the eggless yellow cakes. F1 shows the lowest springiness at 0.85 . A hypothesis made in others study said that the aggregation of protein in the cake crumb is related to its springiness [21]. Hence, due to the total removal of eggs which contains protein from the cake leads to reduced springiness. However, it was found in this study that the addition of a high concentration of xanthan gum (1.5\%) may significantly affect the springiness of the cake. The springiness in control cake and eggless cake with the highest concentration of gum (F3) was found to be not significantly different from one another. Hence, we can conclude that higher gum concentration will increase the springiness of eggless cake and may mimic the same springiness as in the control cake.

For cohesiveness parameter, control and F3 showed significantly the highest cohesiveness at 0.64 and 0.61 . F1 shows the least cohesive at 0.55 , followed by F2 at 0.58 . Based on this result, we are able to conclude that cohesiveness increased with gum concentration. Low gum concentration reduced the internal resistance of the cake compared to control.

In the gumminess parameter, control and F1 showed significantly the least gumminess at 983.61. For the eggless cake, the gumminess increased as the gum concentration increased. F1 showed the least gumminess from the rest of the eggless cake at 1018.55 . F2 with gum concentration of $1.0 \%$ showed gumminess of 1319.07 , an increment by $22.78 \%$ from F1 which contained only $0.5 \%$ xanthan gum. F3 $(1.5 \%$ xanthan gum) showed the highest gumminess at 1411.55 with an increment of $6.55 \%$ from F3. Hence, we can conclude that higher concentration of xanthan gum added increased the gumminess of the cake.

\section{Sensory evaluation}

Table 6 below shows the sensory evaluation results for the experiment. In terms of colour and aroma, there was no significant difference found between the cakes. This proves that in this study, we were able to produce an eggless cake with equal preference from the panellists with the control in terms of its colour and aroma. In terms of the texture and taste, there exists no significant difference between control and F1; in which control received the highest score at 6.90 and 7.06 for texture and taste respectively. F1, on the other hand, received the second-best score for both texture and taste at 6.65 and 6.74, respectively. Hence, we can conclude that most panellists were unable to detect the difference in texture and taste between an eggless cake containing $0.5 \%$ xanthan gum and the control cake. The overall acceptability results showed that panellists were unable to differentiate between control and the eggless cake containing $0.5 \%$ gum as there were no significant difference found between them. Meanwhile, F2 and F3 received a significantly lowest score of 5.81. During the analysis was conducted, the panellists were not told that they were going to taste test an eggless cake in order to avoid biased result. However, based on the results found, we can observe that the panellists still prefer the control cake but at the same time were able to accept the eggless cake, with minimum addition of gum $(0.5 \%)$.

\section{CONCLUSION}

In conclusion, the objectives of this study have been met. It was found that a higher concentration of xanthan gum added to the cake will significantly reduce the moisture content, cake volume, and water activity compared to control. It was also found that the removal of eggs significantly affects the final colour of the product by significantly reducing its lightness and yellowness. The texture of the cakes was also affected in which the higher concentration of gum added, the harder the cake will be. In terms of sensory characteristics, it was found that panellists have an equal preference towards the control cake and the eggless cake containing the least xanthan gum concentration at $0.5 \%$. 
Table 1 Formulation of eggless yellow cake

\begin{tabular}{|c|c|c|c|c|}
\hline Formulation & Control & $\begin{array}{l}\text { F1 } \\
(0.5 \%) z\end{array}$ & $\begin{array}{l}\text { F2 } \\
(1.0 \%)\end{array}$ & $\begin{array}{l}\text { F3 } \\
(1.5 \%)\end{array}$ \\
\hline Xanthan gum & - & $0.5 \mathrm{~g}$ & $1.0 \mathrm{~g}$ & $1.5 \mathrm{~g}$ \\
\hline Eggs & $50 \mathrm{~g}$ & - & - & - \\
\hline Fine granulated sugar & $90 \mathrm{~g}$ & $90 \mathrm{~g}$ & $90 \mathrm{~g}$ & $90 \mathrm{~g}$ \\
\hline All-purpose flour & $100 \mathrm{~g}$ & $100 \mathrm{~g}$ & $100 \mathrm{~g}$ & $100 \mathrm{~g}$ \\
\hline Baking powder & $3 g$ & $3 g$ & $3 \mathrm{~g}$ & $3 \mathrm{~g}$ \\
\hline Milk & $60 \mathrm{~mL}$ & $60 \mathrm{~mL}$ & $60 \mathrm{~mL}$ & $60 \mathrm{~mL}$ \\
\hline Oil & $30 \mathrm{~mL}$ & $30 \mathrm{~mL}$ & $30 \mathrm{~mL}$ & $30 \mathrm{~mL}$ \\
\hline Vanilla essence & $3 \mathrm{~mL}$ & $3 \mathrm{~mL}$ & $3 \mathrm{~mL}$ & $3 \mathrm{~mL}$ \\
\hline
\end{tabular}

*F1: $0.5 \%$ xanthan; F2: $1.0 \%$ xanthan; F3: $1.5 \%$ xanthan based on wheat flour basis ( $100 \mathrm{~g})$.

Table 2 Chemical composition of eggless yellow cake

\begin{tabular}{|c|c|c|c|c|}
\hline & Control & F1 & F2 & F3 \\
\hline Moisture (\%) & $28.87 \pm 0.03^{\mathrm{a}}$ & $26.97 \pm 0.18^{b}$ & $26.18 \pm 0.05^{\mathrm{c}}$ & $25.86 \pm 0.12^{\mathrm{d}}$ \\
\hline Protein $(\%)$ & $7.98 \pm 0.22^{\mathrm{a}}$ & $5.76 \pm 0.08^{\mathrm{b}}$ & $5.54 \pm 0.12^{\mathrm{bc}}$ & $5.47 \pm 0.08^{\mathrm{c}}$ \\
\hline Fat $(\%)$ & $15.68 \pm 0.51^{\mathrm{a}}$ & $9.99 \pm 0.06^{\mathrm{b}}$ & $9.62 \pm 0.44^{\mathrm{bc}}$ & $9.24 \pm 0.20^{\mathrm{c}}$ \\
\hline Ash (\%) & $1.22 \pm 0.04^{\mathrm{a}}$ & $0.82 \pm 0.05^{\mathrm{b}}$ & $0.82 \pm 0.02^{\mathrm{b}}$ & $0.83 \pm 0.01^{\mathrm{b}}$ \\
\hline Carbohydrate (\%) & $46.25 \pm 0.45^{\mathrm{c}}$ & $56.47 \pm 0.29^{b}$ & $57.83 \pm 0.58^{\mathrm{a}}$ & $58.60 \pm 0.25^{\mathrm{a}}$ \\
\hline Water activity & $0.91 \pm 0.00^{\mathrm{a}}$ & $0.89 \pm 0.00^{\mathrm{b}}$ & $0.89 \pm 0.00^{\mathrm{b}}$ & $0.90 \pm 0.00^{\mathrm{b}}$ \\
\hline
\end{tabular}

Values presented are the average obtained from triplicates.

*F1:0.5\% gum; F2: $1.0 \%$ gum; F3: $1.5 \%$ gum.

a-d : Values in the same row with the same letter are not significantly different at $(\mathrm{p}<0.05)$ 
Table 3 Volume of eggless yellow cake

\begin{tabular}{lllll}
\hline & Control & F1 & F2 & F3 \\
\hline Volume $\left(\mathrm{cm}^{3}\right)$ & $523.33 \pm 7.64^{\mathrm{a}}$ & $425.00 \pm 5.00^{\mathrm{c}}$ & $446.47 \pm 10.41^{\mathrm{b}}$ & $443.33 \pm 7.64^{\mathrm{b}}$ \\
\hline
\end{tabular}

Values presented are the average obtained from triplicates.

*F1:0.5\% gum; F2: 1.0\% gum; F3: 1.5\% gum.

$\mathrm{a}-\mathrm{c}$ : Values in the same row with the same letter are not significantly different at $(\mathrm{p}<0.05)$

(a)

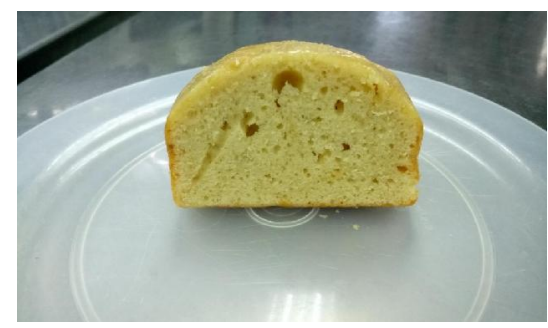

(b)

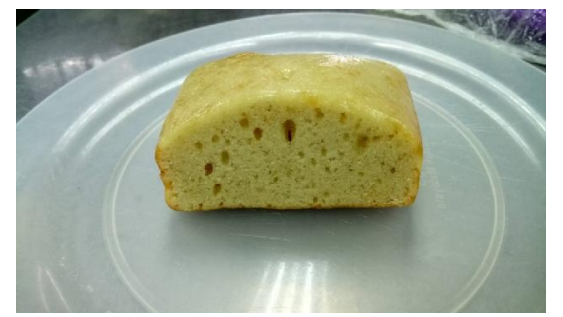

(c)

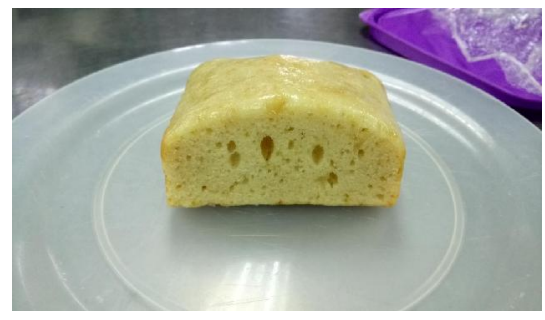

(d)

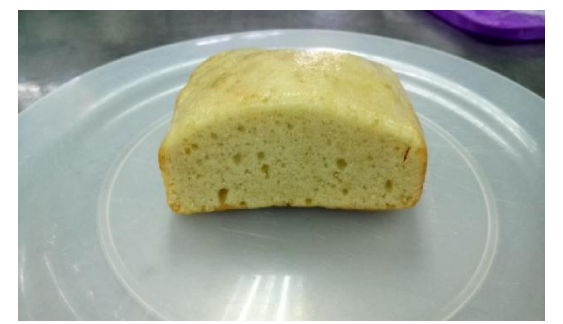

Figure 1 Cross-section of eggless cake (*Note: (a) = Control, (b) $0.5 \%$ gum, (c) $1.0 \%$ gum, (d) = 1.5\% gum

Table 4 Color of eggless yellow cake

\begin{tabular}{lllll}
\hline & Control & F1 & F2 & F3 \\
\hline $\mathrm{L}^{*}$ & $71.32 \pm 0.26^{\mathrm{a}}$ & $65.40 \pm 0.65^{\mathrm{c}}$ & $65.65 \pm 0.28^{\mathrm{c}}$ & $67.25 \pm 0.20^{\mathrm{b}}$ \\
$\mathrm{a}^{*}$ & $-0.08 \pm 0.02^{\mathrm{c}}$ & $0.46 \pm 0.03^{\mathrm{b}}$ & $0.42 \pm 0.03^{\mathrm{a}}$ & $0.51 \pm 0.02^{\mathrm{b}}$ \\
$\mathrm{b}^{*}$ & $27.28 \pm 0.31^{\mathrm{a}}$ & $23.65 \pm 0.27^{\mathrm{b}}$ & $23.19 \pm 0.51^{\mathrm{b}}$ & $23.59 \pm 0.59^{\mathrm{b}}$ \\
\hline
\end{tabular}

Values presented are the average obtained from triplicates.

*F1:0.5\% gum; F2: 1.0\% gum; F3: 1.5\% gum.

a-c : Values in the same row with the same letter are not significantly different at $(\mathrm{p}<0.05)$ 
Table 5 Textural properties of eggless yellow cake

\begin{tabular}{lllll}
\hline & Control & F1 & F2 & F3 \\
\hline Hardness (g) & $1599.66 \pm 84.14^{\mathrm{c}}$ & $1945.69 \pm 40.78^{\mathrm{b}}$ & $2203.41 \pm 72.65^{\mathrm{a}}$ & $2348.45 \pm 146.97^{\mathrm{a}}$ \\
Springiness & $0.90 \pm 0.007^{\mathrm{a}}$ & $0.85 \pm 0.005^{\mathrm{c}}$ & $0.88 \pm 0.007^{\mathrm{b}}$ & $0.90 \pm 0.006^{\mathrm{a}}$ \\
Cohesiveness & $0.61 \pm 0.01^{\mathrm{ab}}$ & $0.55 \pm 0.00^{\mathrm{c}}$ & $0.58 \pm 0.02^{\mathrm{bc}}$ & $0.64 \pm 0.03^{\mathrm{a}}$ \\
Gumminess (g) & $983.61 \pm 10.30^{\mathrm{b}}$ & $1018.55 \pm 68.64^{\mathrm{b}}$ & $1319.07 \pm 50.85^{\mathrm{a}}$ & $1411.55 \pm 80.72^{\mathrm{a}}$ \\
\hline
\end{tabular}

Values presented are the average obtained from triplicates.

*F1:0.5\% gum; F2: $1.0 \%$ gum; F3: $1.5 \%$ gum

a-d: Values in the same row with the same letter are not significantly different at $(p<0.05)$.

Table 6 Sensory evaluation of eggless yellow cake

\begin{tabular}{llllll}
\hline & Colour & Aroma & Texture & Taste & Overall \\
\hline Control & $6.39 \pm 1.26^{\mathrm{a}}$ & $7.00 \pm 1.21^{\mathrm{a}}$ & $6.90 \pm 1.25^{\mathrm{a}}$ & $7.06 \pm 1.06^{\mathrm{a}}$ & $7.23 \pm 1.12^{\mathrm{a}}$ \\
$\mathbf{F 1}$ & $6.81 \pm 1.28^{\mathrm{a}}$ & $7.06 \pm 1.09^{\mathrm{a}}$ & $6.65 \pm 0.99^{\mathrm{a}}$ & $6.74 \pm 1.24^{\mathrm{a}}$ & $6.87 \pm 0.96^{\mathrm{a}}$ \\
$\mathbf{F 2}$ & $6.10 \pm 1.45^{\mathrm{a}}$ & $6.81 \pm 1.20^{\mathrm{a}}$ & $5.26 \pm 1.26^{\mathrm{b}}$ & $5.87 \pm 1.41^{\mathrm{b}}$ & $5.81 \pm 1.28^{\mathrm{b}}$ \\
$\mathbf{F 3}$ & $6.55 \pm 1.31^{\mathrm{a}}$ & $6.81 \pm 1.01^{\mathrm{a}}$ & $5.06 \pm 1.26^{\mathrm{b}}$ & $5.84 \pm 1.37^{\mathrm{b}}$ & $6.03 \pm 1.11^{\mathrm{b}}$ \\
\hline
\end{tabular}

Values presented are the average obtained from 30 panelists.

F1:0.5\% gum; F2: 1.0\% gum; F3: $1.5 \%$ gum.

a-b: Values in the same column with the same letter are not significantly different at $(p<0.05)$

Scale indicator: $5=$ neither like nor dislike, $6=$ Like slightly, $7=$ Like moderately (based on Hedonic scale). 


\section{ACKNOWLEDGEMNT}

The authors would like to thanks Faculty of Applied Sciences, Universiti Teknologi MARA, Shah Alam, Malaysia for the financial assistance, facilities and support throughout this research.

\section{REFERENCES}

[1] Matsakidou, A., Blekas, G., \& Paraskevopoulou, A. (2010). Aroma and physical characteristics of cakes prepared by replacing margarine with extra virgin olive oil. LWT - Food Science and Technology, 43(6), 949-957.

[2] National Food Service Management Institute. (2009). Culinary techniques for healthy school meals (2nd ed.). University, MS: Author.

[3] Dhanapala, P., Silva, C. De, Doran, T., \& Suphioglu, C. (2015). Cracking the egg: An insight into egg hypersensitivity. Molecular Immunology, 66(2), 375-383.

[4] Corrin, T., \& Papadopoulos, A. (2017). Understanding the attitudes and perceptions of vegetarian and plant-based diets to shape future health promotion programs. Appetite, 109, 40-47.

[5] Arozarena, I., Bertholo, H., Empis, J., Bunger, A., \& de Sousa, I. (2001). Study of the total replacement of egg by white lupine protein, emulsifiers and Xanthan gum in yellow cakes. European Food Research and Technology, 213(4-5), 312-316.

[6] Ghashghaei, T., Soudi, M.R., \& Hoseinkhani, S. (2016). Optimization of xanthan gum production from grape juice concentrate using Plackett-Burman design and response surface methodology. Applied Food Biotechnology, 3 (1), 15-23.

[7] Niknezhad, S.V., Asadollahi, M.A., Zamani, A., Biria, D. (2016). Production of xanthan gum by free and immobilized cells of Xanthomonas campestris and Xanthomonas pelargonii. International Journal of Biological Macromolecules, 82 (751), 756.

[8] Lin, M., Hong, S., Yang, H., Yang, B., \& Li, H. (2017b). Replacement of eggs with soybean protein isolates and polysaccharides to prepare yellow cakes suitable for vegetarians. Food Chemistry, 229, 663-673.

[9] Kohrs, D., Herald, T. J., Aramouni, F. M., \& Abughoush, M. (2010). Evaluation of egg replacers in a yellow cake system. Emirates Journal of Food and Agriculture, 22(5), 340-352.

[10] Lin, M., Tay, S. H., Yang, H., Yang, B., \& Li, H. (2017a). Development of eggless cakes suitable for lacto-vegetarians using isolated pea proteins. Food Hydrocolloids, 69, 440-449.

[11] AACC. (2000). Approved Methods of the American Association of Cereal Chemists (10th ed.). St. Paul, MN.

[12] Jeddou, K.B., Bouaziz, F., Zouari-Ellouzi, S., Chaari, F., EllouzChaabouni, S., Ellouz-Ghorbel, R., \& Nouri-Ellouz, O. (2017). Improvement of texture and sensory properties of cakes by addition of potato peel powder with high level of dietary fiber and protein. Food Chemistry, 217, 668-677.

[13] Hwan, J., Jung, H., Lee, H., Lim, E., Imm, J., \& Joo, H. (2012). Physical and sensory characteristics of fibre-enriched sponge cakes made with Opuntia humifusa. LWT - Food Science and Technology, 47(2), 478-484.

[14] Mine, Y. (2008). Egg bioscience and biotechnology. Hoboken, New Jersey: John Wiley and Sons.

[15] Borneo, R., Aguirre, A., \& León, A. E. (2010). Chia (Salvia hispanica L) gel can be used as egg or oil replacer in cake formulations. Journal of the American Dietetic Association, 110(6), 946-949.

[16] [16] Fernandes, S. S., \& Salas-mellado, M. D. M. (2017). Addition of chia seed mucilage for reduction of fat content in bread and cakes. Food Chemistry, 227, 237-244.

[17] Janjarasskul, T., Tananuwong, K., \& Kongpensook, V. (2016). Shelf life extension of sponge cake by active packaging as an alternative to direct addition of chemical preservatives. LWT - Food Science and Technology, 72, 166-174.
[18] Gòmez, M., Ronda, F., Caballerro, P.A., Blanco, C.A., \& Rosell, C.M. (2007). Functionality of different hydrocolloids on the quality and shelf-life of yellow layer cakes. Food Hydrocolloids, 21, 167173.

[19] Sahraiyan, B., Naghipoor, F., Najafi, M.B.H., Karimi, M., Khodaparast, M.H.H., \& Davoodi, M.G. (2015). Production of eggless cake. Ferdowsi University of Mashhad. ResearchGate.net.

[20] Tan, M. C., Chin, N. L., Yusof, Y. A., Taip, F. S., \& Abdullah, J. (2015). Improvement of Eggless Cake Structure Using Ultrasonically Treated Whey Protein. Food and Bioprocess Technology, 8(3), 605614.

[21] Wilderjans, E., Pareyt, B., Goesaert, H., Brijs, K., \& Delcour, J. A. (2008). The role of gluten in a pound cake system: A model approach based on gluten-starch blends. Food Chemistry, 110(4), 909-915. 